\title{
Palliative ("Toilet") Mammectomy, A Decision-Making Dilemma - Short Review
}

\author{
Adrian Constantin ${ }^{1,2^{*} \sharp}$, Dragoș Predescu ${ }^{1,2 \sharp}$, Ruxandra Ciofu ${ }^{3}$, Florin Achim ${ }^{1,24}$, Silviu Constantinoiu ${ }^{1,2}$ \\ ${ }^{1}$ Center of Excellence in Esophageal Surgery, "Sf. Maria" Clinical Hospital, Bucharest, Romania \\ ${ }^{2}$ Carol Davila University of Medicine and Pharmacy, Bucharest, Romania \\ ${ }^{3} 2^{\text {nd }}$ Surgery Department, "Sf. Maria" Clinical Hospital, Bucharest, Romania
}

*Corresponding author:

Adrian Constantin, MD, Ph

Center of Excellence in Esophageal

Surgery, "Sf. Maria" Clinical Hospital

Bucharest, Romania

E-mail: dradiconstantin@yahoo.com

\section{Rezumat \\ Mamectomia de toaletă, o dilemă decizională - short review}

Cancerul de sân este una dintre cele mai importante probleme de sănătate în întreaga lume, dar la care progresele resurselor terapeutice au schimbat major prognosticul, în paralel cu adaptarea permanentă a protocoalelor de tratament. In acest articol sintetizăm managementul terapeutic al neoplasmului de sân avansat local, în paralel cu revizia literaturii de specialitate, din perspectivă chirurgicală, astfel încât să identificăm şi să plasăm optim locul, rolul şi beneficiile acesteia în terapeutica oncochirurgicală. Locul chirurgiei devine controversat, cu tehnici uneori "pretențioase", cu beneficii dificil de cuantificat, cu provocări ce impun o minuțioasă evaluare care să preceadă indicația operatorie. Interesantă este şi relativa "lipsă" din ghiduri a acestor cazuri, de un plurimorfism lezional extrem. Acesta este de altfel motivul pentru care termenul de cancer de sân avansat local NU poate cuprinde toate situațiile posibile, lasând loc unor situații de nişă, care nu sunt încadrabile facil într-un plan terapeutic.

Cuvinte cheie: cancer de sân, cancer avansat şi complicat local, mamectomie de toaletă

\section{Abstract}

Breast cancer is one of the most severe health issues globally, but the therapy advancements and the constant adaptation of treatment protocols radically changed its prognoses. This article 
is a synthesis on the management of locally advanced breast neoplasms, in parallel with a review of the literature from a surgical perspective, thus allowing for the optimum detection and placement of its role and benefits in the surgical and oncology therapeutics. The role of surgery becomes controversial, with sometimes "pretentious" techniques, hard to quantify benefits and challenges that require a thorough assessment prior to opting for surgery. Another interesting aspect is the relative lack of guidelines for such cases with an extreme lesion plurimorphism. This is the very reason for the term "advanced breast cancer" NOT covering all possible situations, leaving room for niches difficult to frame within a therapy plan.

Key words: breast cancer, locally advanced and complex cancer, toilet mammectomy

\section{Introduction}

With 1.3 million new cases and almost half a million deaths annually, breast cancer is one of the most important health concerns, especially in developed countries (1).

According to the World Health Organisation International Cancer Research Agency, as stated on the Global Cancer Observatory platform (GLOBOCAN 2018), the breast cancer held, in 2018 , the first place in Romania, with $25.1 \%$ new cases, as well as the first place in cancer-related deaths (2).

While hormonal therapy, chemotherapy and anti-HER-2 therapies lowered the recidivation risk in the incipient stages, therapy failures are recorded in a significant number of cases, and the average survivability is still of 2-3 years for metastasised cancers (3-5). Therefore, the management of advanced cancers is still a significant problem in oncology. Whereas at present, the curative therapy of such cases seems to be far in the future, the main objective of therapy remains the optimum palliation, along with prolonging the survivability and ensuring an adequate quality of life for the patients (6).

Over the last decade, breast cancer mortality decreased substantially thanks to the improvement of medical education, the implementation of screening/diagnostic protocols, multimodal customised treatments, and optimised monitoring (7).

Surgery is present, with various approaches, in all treatment protocols. While its techniques and indications are almost standardised in incipient stages, advanced stage tumours may lead to controversy. Locally advanced neoplasms are our subject, oftentimes impressively such, ulcerating, with various degrees of haemorrhages, involving extra-mammary invasions of the chest wall, with indications, surgery time and technical difficulties turning into real challenges as the local neoplastic impact progresses (8). We should not neglect, therefore, the secondary systemic, biological and quality of life-related impact. Therefore, a priori, the toilet mammectomy defines a resection technique WITHOUT a direct oncology-related objective, but an effective control of local complications resulting from large tumours. The primitive tumour control using the toilet mammectomy, while its impact on the oncological evolution of the disease is controversial, seems, according to numerous studies, to improve the survivability, with its speculative mechanism being the overall reduction of the neoplastic mass and the improvement of the biological status, allowing for optimising the dosage and number of treatments in an oncology treatment (9).

\section{Guidelines and Terminology}

The cancer staging reporting was subject to continuous evolutions and adjustments, with the latest data reported by AJCC and UICC ( $8^{\text {th }}$ edition, 2018) resulting in many additional and new, clarifications. The strategy is based on correlating and integrating the cancer staging 
and prognosis systems, together, not independently. Its impact is therapeutic, of course, due to new and varied oncological and surgical management protocols. The most important change is, perhaps, the introduction of the prognosis factors and their varied association to the TNM staging of the oestrogen (ER) and progesterone (PgR) hormonal receptors' expression, as well as of the human epidermal growth factor -2 (HER2).

We can detect a number of terminology issues, oversights, discrepancies, or mix-ups related to the definition of neoplastic breast disease and, more precisely, of the tumour stage. This is the reason for AJCC creating a better correlated with the stage of the disease definition of a tumour stage, based not only on anatomic considerations or criteria (using only $\mathrm{T}, \mathrm{N}$, and $\mathrm{M}$ ), thus recommending using such considerations or criteria exclusively in situations when determining the grading and/or specific biomarkers (HER2, ER, PR) is impossible. Such situations are by no means seldom, as they characterise regions where the healthcare systems cannot offer such information. Correlating additional criteria with the tumour stage ( $\mathrm{G}$ and, respectively, the HER2, ER, PR biomarkers) contributed to refining the assigning all patients to the so-called clinical prognostic stage and using the pathological prognostic stage only for surgery patients, based on the surgical resection samples.

The inclusion of the disease prognosis in the malignancy staging lead to some semantic and terminology complications concerning commonly used terms such as: incipient vs. advanced breast cancer, locally advanced cancer vs. metastatic advanced cancer, complex vs. simple locally advanced cancer (11).

A particular issue, further complicating the therapy management decision-making is, on one side, the asymmetry of the international guidelines' recommendations, as well as the development of national guidelines, and on the other side, the inability to assign all possible "extreme", due to the lesion plurimorphism, situations to a particular stage. It is interesting to note that, as far as surgery is concerned, the discrepancies in recommendations are minimal, targeting only the oncologically safe free margin between the tumour and the remaining adjacent tissue. It is, apparently, a natural choice, as the surgical options are fewer compared with the oncological ones, but, when talking about a locally extended lesion, accompanied by superinfected and/or haemorrhaging parietal chest destruction, surgery seems to be missing or to be relegated to a secondary, unclearly defined, position. Moreover, the absence of the approaches for complex situations, such as sepsis or complex sepsis resulting from such ulcerating tumours or acute or chronic, more or less aggressive, haemorrhages, from the major guidelines seems imprecise and even worrying. As for improving the patient's quality of life under such medical circumstances, the "how" of local or systemic therapy associated with oncological treatment is only specified under "patientadapted therapy". This is probably why the specialists' consensus is significantly lower (approx. 70\%). However, the attention to details is not lacking, considering the in-depth approach of fertility, dyspareunia, sexual health and post-menopausal management issue. These grey areas are, most probably, the result of a meagre number of locally advanced and surgically or systemically complex neoplasms in Western statistics (10).

Despite the constantly improving monitoring programmes, $10 \%$ of the breast cancers include, upon diagnosis, over 5 - $\mathrm{cm}$ tumours, tegumental or chest wall invasion and axillary or internal mammary adenopathies. The locally advanced breast cancer definition is not standardised, but most authors refer to stages IIB, IIIA and IIIB. From a practical point of view, the advanced breast cancer concerns the cases when the therapy protocol does not include radical mammectomies. The acute carcinomatous mastitis is a separate clinical entity, with different prognosis and evolution, included in the locally advanced cancer category due to the similar therapy approach. From a clinical standpoint, it is defined by the presence of the local erythema, orange peel teguments, and from a histopathological perspective, by the lymph ducts' invasion $(12,13)$. 
While the literature data are incomplete, the consensus indicates, in the majority of such cases, pre-operative chemotherapy with anthracyclines accompanied or not by taxanes, followed by a total mammectomy, axillary lymph node dissection and radiotherapy, somewhat irrespective of the sometimes monstrous macroscopic aspect, modified by the local complications resulting from the parietal juxta-mammary structures invasion. The surgery site for such advanced stages is almost standardised in indications and techniques. Even a conservative technique may be considered in the case of an adequate response to the neoadjuvant therapy, whenever the histology prognosis factors are favourable. The subsequent evolution of survivability and quality of life-related prognosis follows the path of the oncological disease prognosis $(14,15)$.

The differences occur when voluminous tumour-specific complications (sepsis, haemorrhages) appear, complications that, when not controlled, lead to a different disease evolution, diverging from the neoplastic disease evolution. There are data about cases when the tumour's septic status or the tumoral haemorrhagic syndrome have a more pessimistic prognosis, in terms of survivability than the actual oncological prognosis without such complications (Fig. 1). In most cases, in such situations, the speedy decision towards ablating the septic or haemorrhaging neoplastic nidus is required, as the case's urgency is formal.

On the other hand, such complications may occur at any point of the neoplastic disease management. Whenever occurring during or immediately after a radiotherapy technique, an additional issue of solving the tissue defects is subsequent to the surgical resection technique. The cicatrisation phenomena need to be assessed from the point of view of postradiotherapy-specific particularities (16).

\section{Suppurative phenomena}

The ulcerating tumours are susceptible to superinfections, becoming painful and fetid. Such phenomena are due, without limitation, to anaerobic germs involvement (17-21). The most frequently isolated anaerobic germ is Bacteroides sp. There are cases when Fusobacterium sp, Peptococcus sp and Peptostreptococcus sp. were also isolated (18, 19). Such anaerobic germs are normal to the saprophytic flora and normally non-virulent; however, they become aggressive in cases of immunosuppressed hosts. When combined with a locally deficient blood hypoperfusion, necrotic tumoral tissue becomes an ideal culture medium for such germs (Fig. 2). The lipid degradation products, influenced by the aerobic germs, become a source of energy for the anaerobic flora. The lipidic catabolism produces acetic, propionic, isobutyric, butyric, isovaleric and valeric acids. All these products

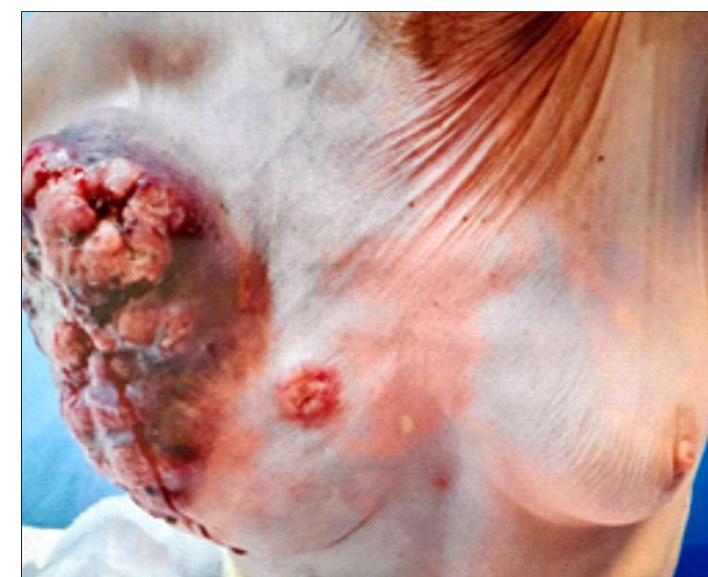

Figure 1. A locally advanced breast neoplasm case, with extended invasion, including the chest wall (teaching hospital media library)

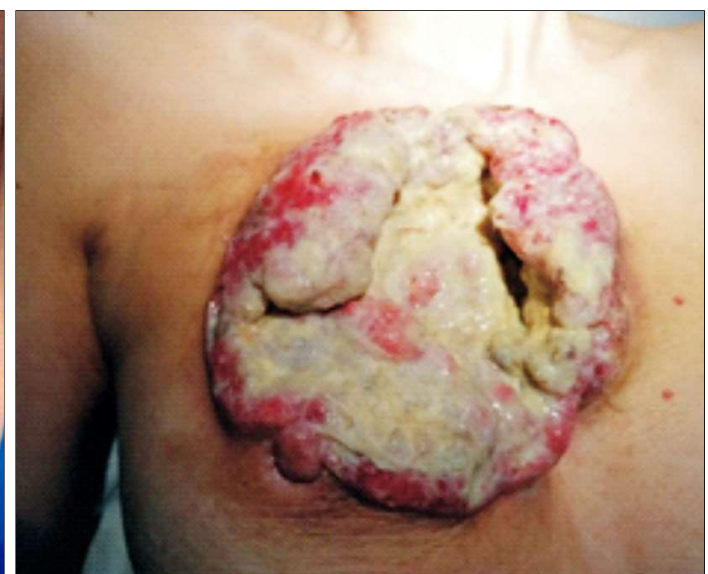

Figure 2.

Locally advanced breast cancer, superinfected, pre-therapy overview (teaching hospital media library) 
form the basis for local fetidity phenomena.

The most frequently used antibacterial agent was orally administered metronidazole (20-23). Despite its documented efficiency, metronidazole treatment leads to gastrointestinal disturbances (nausea, anorexia, vomiting, diarrhoea), leukocytopenia, peripheral neuropathy (24).

The local metronidazole-based treatments (solutions, gels) proved relatively effective against anaerobic germs infections in avoiding systemic adverse reactions; however, the number of known cases with such benefits is limited (25-28). The patient's eligibility for oncological treatment and the positive response to therapy may lead to a surgical "conversion" from the initially considered toilet mammectomy to radical surgery (Fig. 3).

Local bleeding. When haemorrhaging tumours are present, the local, non-surgical control of blood loss is in most cases inefficient, leading to anaemic syndrome, biological debility and, subsequently, to a failure to compile an efficient oncological treatment. The improvement of the overall biology in the context of blood loss might prove impossible, especially for blood groups with limited transfusion stock (Fig. 4). Haemostatic radiotherapy may be considered, but its efficiency is not constant, and its effects show at a slow pace (29).

Topical treatments containing zinc hydrochloride and zinc oxide have been proven to be relatively effective, with no significant side effects; however, in this case too, the number of known cases is limited (30). Moreover, the tumoral blood loss may be persistent at a low flow or due to the tumoral inclusion of a large blood vessel; in such cases, surgical haemostasis (potentially using a laborious surgical technique - see Fig. 5) is required urgently. The debilitating haemorrhaging nidus ablation allows for performing an objectively assessed, specific oncological treatment, adequate to the disease stage (Fig. 6).

\section{Local pain}

Appears in locally advanced tumours due to the inclusion of local and regional nerve structures and to local superinfections. Most
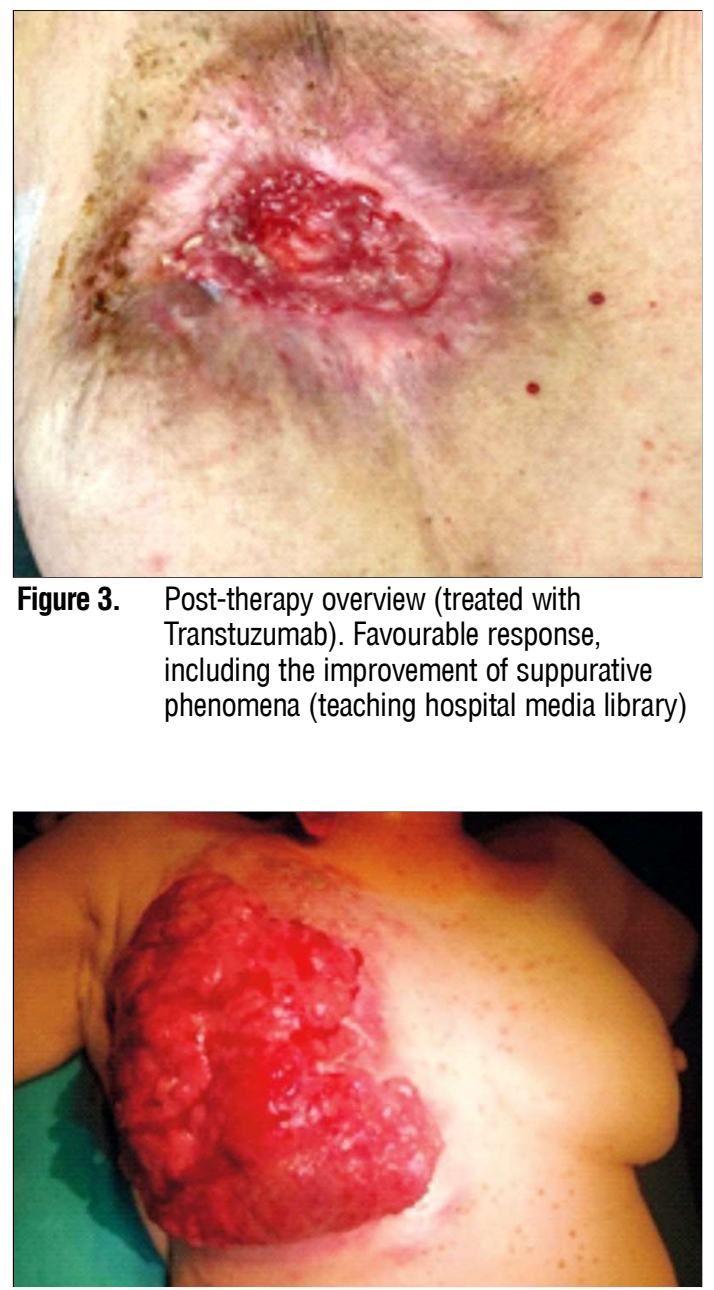

Figure 4. Haemorrhaging breast tumour, stage IV, substantial anaemic syndrome ( $A B$ negative patient) (teaching hospital media library)

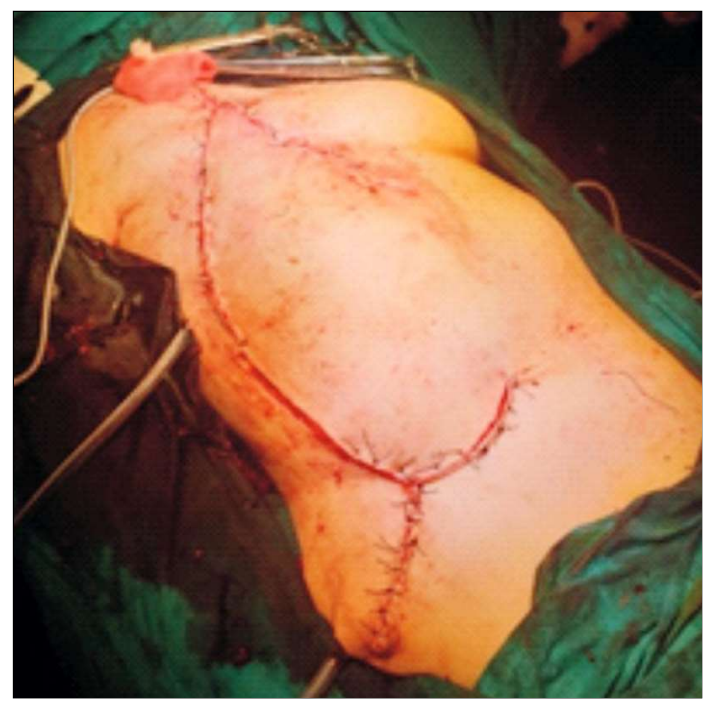

Figure 5. Intra-operative view upon surgery completion (teaching hospital media library) 


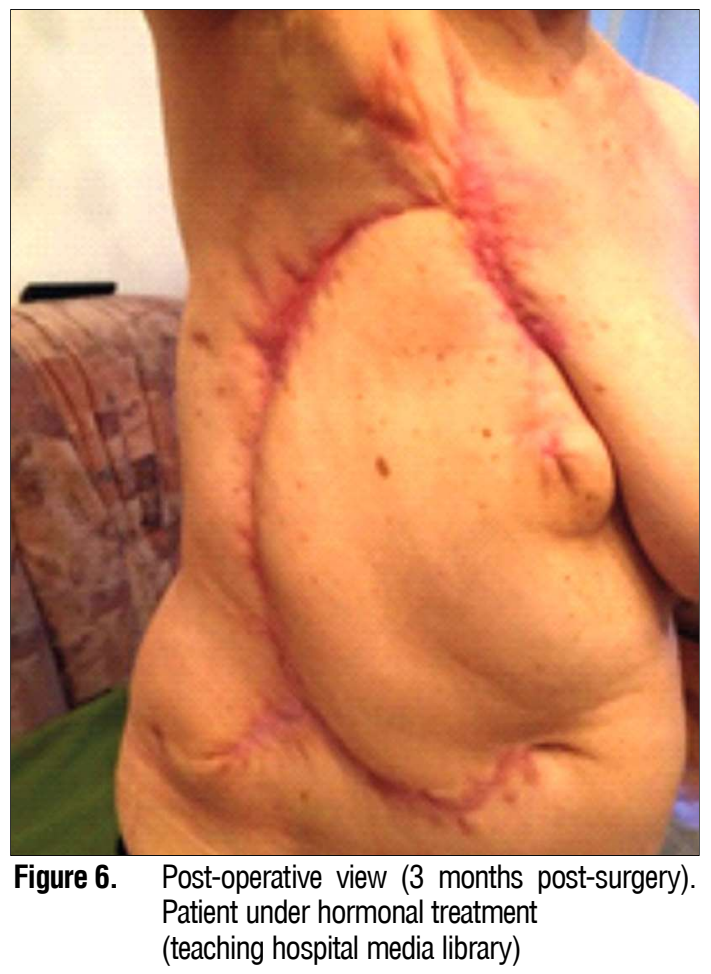

often, it is controlled with systemic antalgic drug treatments and systemic and local antibiotic therapy. If a toilet mammectomy is decided, non-invaded resection margins are required. Failing to meet this goal may lead to recidivations within few weeks, accompanied by pain levels more intense than the initial levels $(31,32)$

All these phenomena and others directly linked to the local complications caused by voluminous tumours define the patient's highly subjectively assessed quality of life. Many aspects of a lower quality of life may add to this: the general discomfort, the wound's aggressive odour, the repeated wound cleaning and everything it involves (going to a healthcare provider, time, availability, etc.), the motor impact, the upper limb mobilisation etc. The tumour resection firmly impedes their development, but we must note that no surgery, however small, cannot be anodyne in case of neoplasm patients, with actual health issues.

\section{The Toilet Mammectomy}

From the nosology framework standpoint, we must note that the toilet mammectomy is not formally adequate in all cases of locally advanced breast neoplasms. Its goal is to control, by removing the tumoral mass, complications related strictly to the neoplasm. Although from a nosology framework standpoint, including the axillary lympha-denectomy is not comprised in the toilet mammectomy definition. It is often included in practical settings, whenever possible, if it doesn't significantly increase surgery's magnitude. The surgery time is set on a case-to-case basis, and it's always in line with the oncological therapy protocol, also depending on the time the complications occurred.

All these aspects render the toilet mammectomy difficult to standardise as an indication, and makes quantifying its benefits difficult, too. In most situations, the decision to perform it is punctual, on a case-to-case basis, depending on the case specifics. Moreover, the literature presents, most often, particular cases, in limited numbers, making statistically relevant conclusions impossible. As a result, attempting to include them in standardised protocols seems to be destined to fail. However, this technique is well-known and was used in surgery for decades; therefore, it seems re-tracing some nuances and clinical indications principles is required.

\section{Surgical technique}

From a technical point of view, it infers resecting the entire visible lesions, with tegumental safety margins of approx. $2 \mathrm{~cm}$. The resection margins without a tumoral infiltration are an important objective, especially when localised pain is present. Destructing all possible tumour cells remaining in the surgical wound is as important, and some authors recommend using abundant intra-operative lavage with hypersaline solutions (Fig. 7 ). Local recidivations, possible within few weeks following a toilet mammectomy, closely related to the resection margin status, often lead to levels of local pain higher than the pre-operative levels. Moreover, as far as the oncological prognostic is concerned, when study results discrepancies are known, it seems than in most cases, if a 


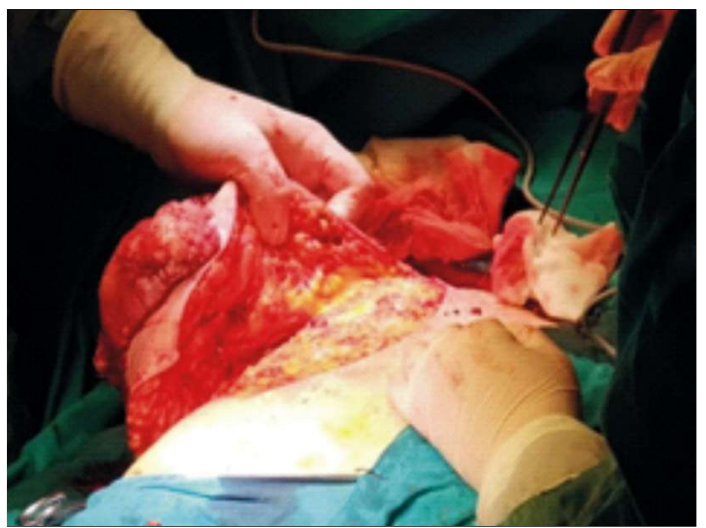

Figure 7. Intra-operative view. Toilet mammectomy (teaching hospital media library)

survivability benefit is reported, it occurred in cases when the resected piece had non-invaded resection margins, even when using limited excision techniques $(33,34)$.

A specific matter is represented by the tactics and techniques used to repair the tissue defects resulting from the tumour resection. There is no standardisation, nor a hierarchy for this issue, either. Decisions are made depending on the resulting parietal defect, and the surgical team's level of expertise (including a plastic surgeon) is decisive. The simple suture of tegumental flaps (possibly after their mobilisation), using tegument grafts, cutaneous or musculocutaneous local and regional flaps, as well as the insertion of various alloplastic materials (possibly connected to a continuous-operation suction system) are a real challenge in terms of options (Fig. 8). The decisions are taken on a case-to-case basis, and the literature presents particular cases, without any set decisionmaking protocol (35).

On the other hand, the toilet mammectomy is and should remain an easy-to-perform technique, involving a limited "surgical aggressivity", followed by the patient's quick recovery and the prospective of initiating or resuming a specific oncological treatment in the near future, once the local complications are eliminated and the patient's biological status was optimised following the tumour resection. In this respect, whenever possible, the parietal defect must be closed using a sim-

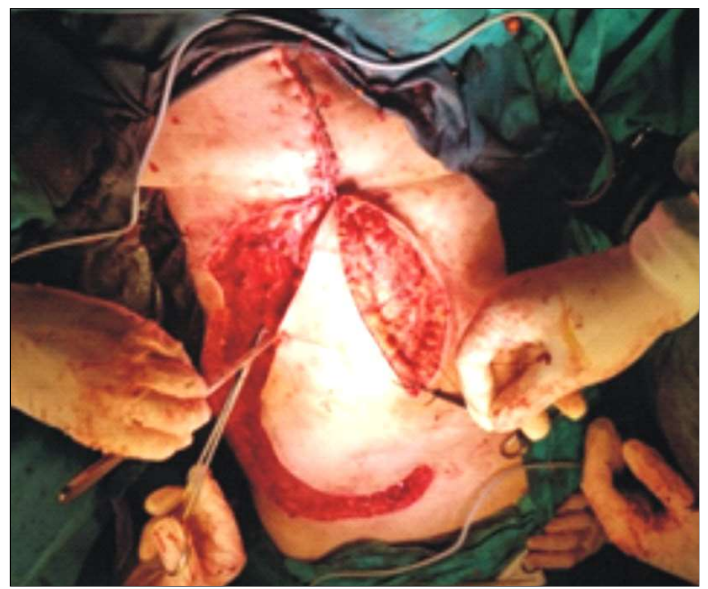

Figure 8. Intra-operative view. Reconstruction using an abdominal flap

(teaching hospital media library)

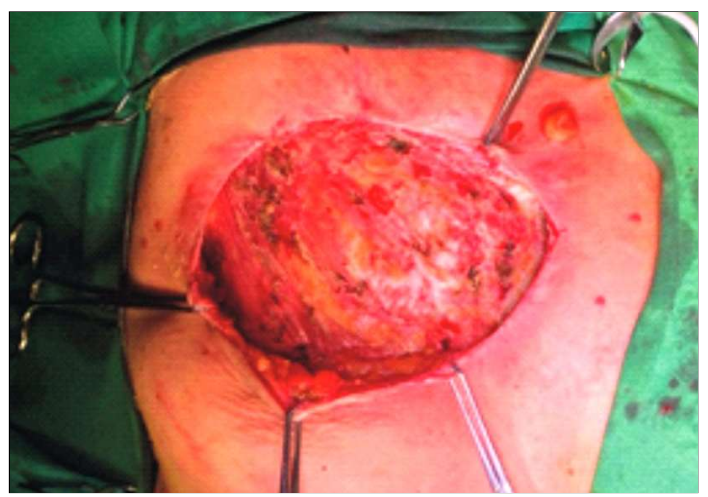

Figure 9. Toilet mammectomy - intra-operative view (teaching hospital media library)

ple suture of the wound margins, possibly after a supra-fascial dissection mobilisation of the tegumental flaps $(31,32,48)$ (Fig. 9).

The improper appreciation of the suture tension leads to a post-operative surgical parietal wound dehiscence, followed by a cascading series of reparatory surgical techniques and to losing the potential benefits, thus becoming distressing for the patient, costly in terms of case management and leading to delaying and even abandoning any (initially planned) oncological treatment plan (Figs. 10, 11, 12).

For the major post-mammectomy parietal defects, the selection of the reconstructive method depends on the defect site and size and the availability of pedunculated flaps. Skin grafts may be used for superficial chest 


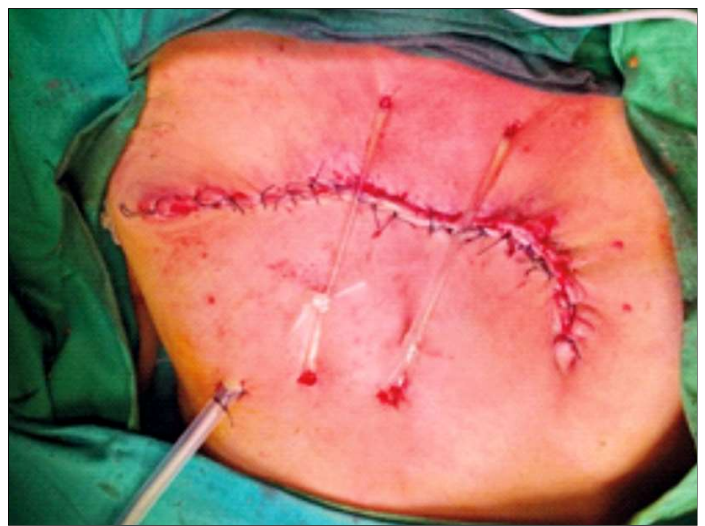

Figure 10. Intra-operative view - surgery completion (excision and tegumental flaps suture) (teaching hospital media library)

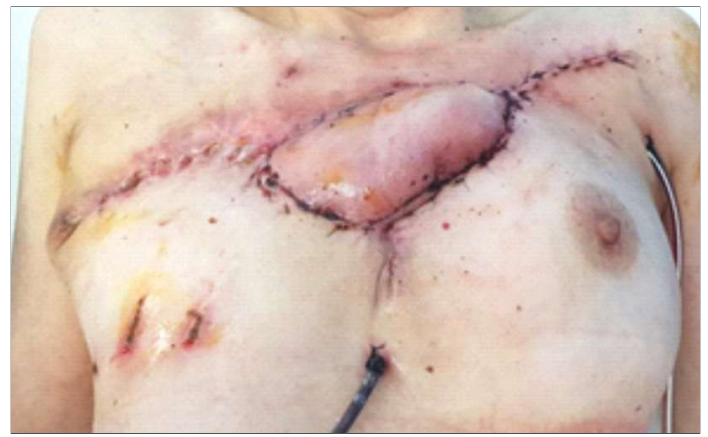

Figure 12. Post-corrective-surgery view. Using the pre-pectoral tegumental flap to cover the dehiscent surgical wound (teaching hospital media library)

wall defects involving only the soft structures. Previous or early post-operative radiotherapy may, however, lead to compromising such grafts (33). The contralateral mammary parenchyma may be used for covering local tissue defects, especially on the medial line. Such flaps are adequate for elderly patients with comorbidities, thanks to their smaller surgical scope. The vascularisation is good, but the aesthetic result is not great (36).

The lateral chest tegumental flap can cover small and medium anterior and lateral defects and may be used in association with other flaps (Fig. 5). It is also useful in elderly patients with precarious biological status. The weakness of this technique is the impossibility to cover major tissue defects (33).

The pedunculated regional musculocutaneous flap available for reconstruction includes

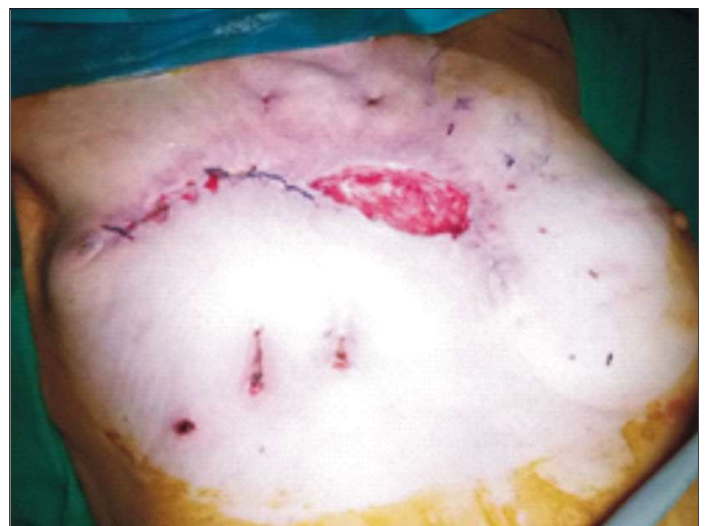

Figure 11. Post-operative view (approx. 10 days post-op) - partially dehiscent surgical wound (teaching hospital media library)

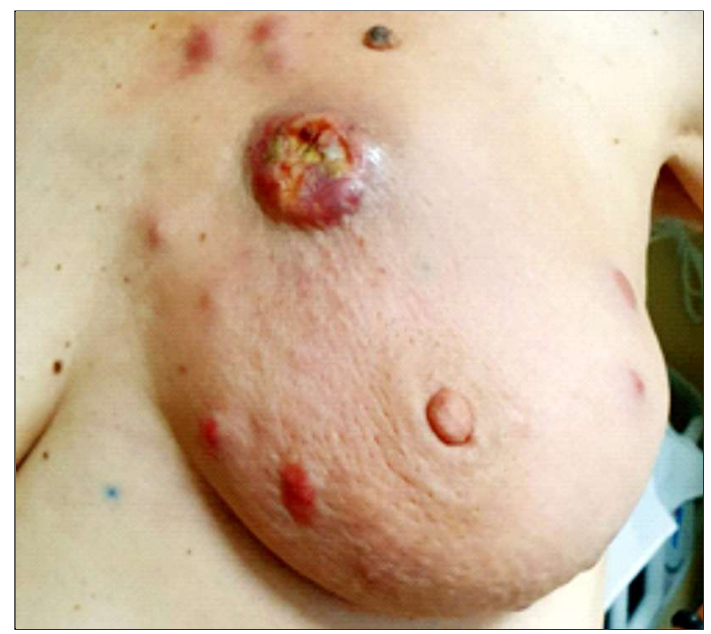

Figure 13. Pre-operative view - breast neoplasm with cutaneous invasion and no local complications (teaching hospital media library)

the latissimus dorsi, and it is, generally, adequate for covering large defects. The flap can be rotated; it's easy to prepare and may be positioned in a manner that covers anterior, posterior and lateral chest defects. It doesn't involve long surgery time and significant postoperative complications (33) (Figs. 13, 14, 15, 18).

However, oncological plastic surgery leads to another level of invasiveness and availability in cases where a toilet mammectomy is indicated. It depends on previously performed radiotherapy and surgical techniques, the patient's overall status and, last but not least, on a pluri-disciplinary team (including, as a requirement, a plastic surgeon). On the other hand, the duration of the recovery and the 


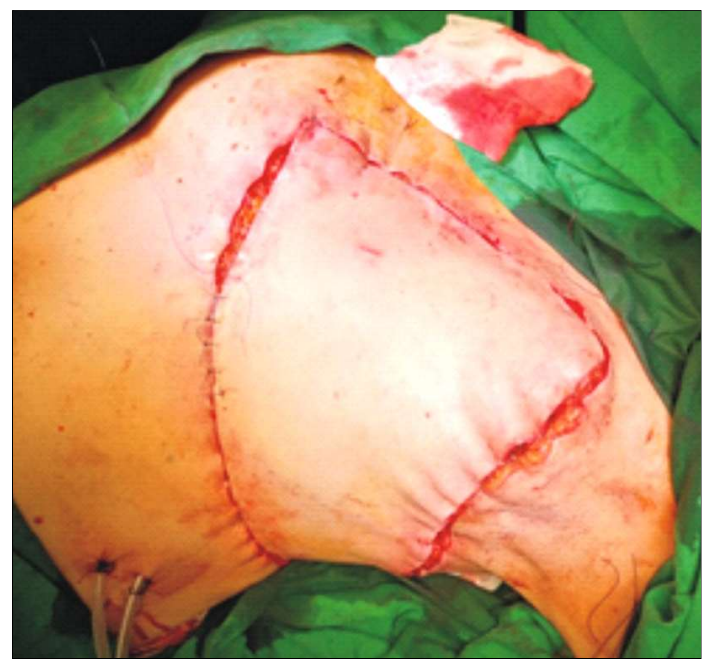

Figure 14. Intra-operative view. Musculo-cutaneous flap reconstruction including the latissimus dorsi (teaching hospital media library)

limitations to the oncological treatment options (radiotherapy may compromise skin grafts and cutaneous/musculo-cutaneous flaps with limited viability) requires a prudent approach in selecting oncological plastic surgery, along with an in-depth assessment of the procedures' medical benefits $(33,36,49)$.

\section{Discussion}

From the point of view of the toilet mammectomy's evolution in managing locally advanced breast tumours, if for decades it was deemed a "heroic" procedure, aiming strictly at improving a patient's comfort besides the real oncological treatment resources, at this point, we can determine another aim for it. The breast formation resection, major source of discomfort and significantly debilitating from a biological standpoint, provides the oncology with the opportunity to create an optimised treatment course that might, even if indirectly, change the patient's prognostic.

Post-operative therapy includes hormonal therapy in cases with positive hormone receptors. Additional chemotherapy may prove opportune depending on the pre-operative treatment. In elderly patients with substantial comorbidities, neoadjuvant hormonal

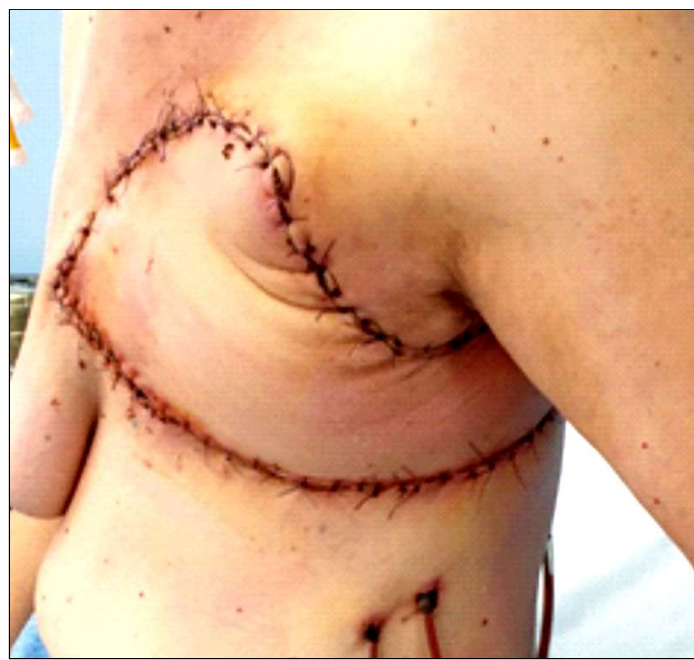

Figure 15. Post-reconstruction post-operative view (teaching hospital media library)

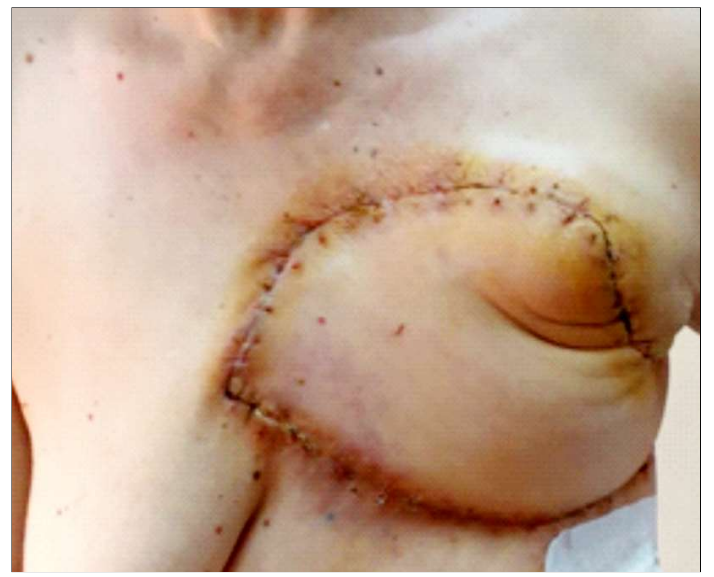

Figure 16. Post-reconstruction distanced view (teaching hospital media library)

therapy is a viable option in the case of positive hormone receptors (37). This multimodal approach radically changed these stages' prognoses, with survivability of up to 5 years percentage in the $40-60 \%$ range, compared to less than $10 \%$ for one-time local treatment. Moreover, the primitive tumour resection is deemed to have a real immunomodulating effect. It leads to a decrease in the overall tumoral mass and removes an important source of new metastases.

On the other hand, the previously accepted quick decision to perform a toilet mammectomy was due to the limits of effective oncological 
treatment resources (chemotherapy) in such cases, as well as to the reservations in administering chemotherapy to patients with voluminous tumoral masses, with chronic sepsis and subsequent biological debilitation.

The evolution of the oncological treatment guidelines towards chemotherapy effectiveness and tolerance, the introduction of targeted treatments, monoclonal and hormonal, provide an opportunity to include such patients in already established treatment schemes, with the tumour resection to be used only in cases with no significant response to therapy and persistent, uncontrollable, local complications. Logically, in line with striving to make oncological treatment effective, it is recommended to establish the oncological treatments as first intent, while continuously monitoring their results and delaying a resection, if possible, until the therapy is completed. The intent to quickly improve the patients' comfort through a surgical resection must be mitigated up to the moment when the patient's responsivity to treatment is determined. We must consider objectively that the patient's quality-of-liferelated tolerance threshold is high, as it was, logically observed, a reason for the disease being previously neglected.

An important controversial subject is the strictly oncological benefit of a resection technique supposed to be effective only in managing local complications. The studies' results often diverge.

Several retrospective studies highlighted an improvement in survivability in stage IV breast cancer patients, in the context of a therapy approach of the primitive tumour. A French study conducted by Pons-Tostivint et al. in 2019 infers a 35\% improvement of the survival rate following the local surgical treatment in patients with metastasised mammary neoplasms. The study focuses on the tumoral sub-type, the number and location of the metastases, and the total tumoral mass as predictive factors. It is also important to note that the primitive tumour approach didn't change triple-negative patients' results. Also, the results were better in cases with only one metastasis. There were no benefits recorded initially in cases with more than two metastases (42). A 2019 Hong Kong study conducted by Co et al. reports a $10 \%$ survivability improvement when the primitive tumour was approached (local-regional treatment) in cases of metastatic stage breast neoplasm. This study highlighted multiple metastases and advanced age as unfavourable factors, while the positive prognostic factor highlighted was the presence of the oestrogen receptors (43).

A meta-analysis of 30 observation studies conducted by Xiao et al. in 2018 highlighted an obvious improvement of survivability following local treatment, especially in the patients with negative margins, with one metastasis or only bone metastases (44). Another American study conducted by Wong et al. also documents improved survivability in HER2+ patients, following the resection of the primitive tumour (45)

In 2020, Gera et al. communicated the results of a primitive breast tumour resection meta-analysis in patients with stage IV breast cancer, reporting a $31.8 \%$ decrease in mortality. Thus, it is recommended to consider multidisciplinary team surgical treatments for selected metastatic stage patients. The study is an additional motivation for the molecular mechanism identification efforts, a type of mechanisms the insemination and development of distant metastases is based on, with the explicit objective of identifying the cases where a primitive tumour resection is beneficial (46).

From this new perspective, it is justifiable to ask ourselves if the toilet mammectomy (including by definition the primitive tumour resection) shouldn't be promoted from a simple therapy for local complications to an effective weapon against neoplasms and for advanced stages. However, until then, it is clear that the nosology framework of this surgical entity become vague, in parallel with the non-surgical oncological treatments' evolution. Actually, suppose we consult the literature for therapy protocols results. In that case, we will notice that, despite the treatment guidelines recommendation to reserve the stage IV mammectomies for cases where local 
palliation is required, approximately $40 \%$ of the patients were subjected to mammectomies after their oncological treatment was completed. Moreover, over $20 \%$ of them had surgical treatment as the first step of therapy. It is unlikely that all these women needed local surgical palliation. Including surgery in the therapy protocol for advanced stages, frequently noticed in the medical practice, frequently remains undocumented, certainly motivated by benefits most often speculated (47).

\section{Conclusions}

The advanced breast cancer treatment involves, in most cases, a neoadjuvant treatment followed by an oncology-sanctioned surgery. However, in some situations, due to local complications (often secondary to the voluminous tumoral mass), a toilet mammectomy is required for their effective management. The toilet mammectomy benefits concern, essentially, improving the patients' quality of life and biological status. Its oncological benefits remain controversial. The indirect benefit, via the patient's eligibility for an effective oncological treatment, after the correction of their biological status, are a logical deduction. The direct benefit, by reducing the overall tumoral mass and by removing a source for metastases, while speculated, should be documented in targeted studies. The technical difficulty of a toilet mammectomy is vast, from a simple technique (resection followed by tegumental suture) to complex surgical procedures requiring a multidisciplinary surgical team, as well as often difficult post-operative care and prolonged hospitalisation.

\section{Author's Contributions}

Adrian Constantin and Dragos Predescu are the main authors

\section{Conflict of Interest}

The authors declare no conflicts of interests.

\section{Ethics Approval}

All procedures performed were in accordance with the ethical standards of the 1964 Helsinki Declaration and its later amendments.

\section{References}

1. Bray F, Ferlay J, Soerjomataram I, Siegel RL, Torre LA, Jemal A. Global cancer statistics 2018: GLOBOCAN estimates of incidence and mortality worldwide for 36 cancers in 185 countries. CA Cancer J Clin. 2018; 68(6):394-424

2. GLOBOCAN 2018. International Agency for Research on Cancer - IARC (http://gco.iarc.fr/today) World Health Organization.

3. EUCAN 2018. The European Cancer Observatory (ECO, http://eco.iarc.fr)

4. Meena PS, Ameta A, Sethi D, Sethi A. A study of locally advanced breast cancer management in patients with rural background. International Journal of Surgery Science 2019;3(4):400-404

5. National Cancer Institute. Surveillance, Epidemiology, and End Results (SEER) Program. Cancer stat facts: female breast cancer. Available at: https://seer.cancer.gov/statfacts/html/breast.html. Accessed June 17, 2020.

6. Park JS, Ahn SH, Son BH, Kim EK. Using local flaps in a chest wall reconstruction after mastectomy for locally advanced breast cancer. Arch Plast Surg. 2015:42(3):288-94

7. Claessensa AKM, Ibragimova KIE, Geurtsa S ME, Bosd M EMM, Erdkampc LG F, Tjan-Heijnena V CG. The role of chemotherapy in treatment of advanced breast cancer: an overview for clinical practice. Crit Rev Oncol Hematol. 2020;153:102988.

8. Dharkar DV, Moses S. Palliative Mastectomy Revisited. Indian J Palliat Care. 2018;24(3):359-361.

9. Soran A, Ozmen V, Ozbas S, Karanlik H, Muslumanoglu M, Igci A, et al. A randomized controlled trial evaluating resection of the primary breast tumor in women presenting with de novo stage IV breast cancer: Turkish Study (Protocol MF07-01). J Clin Oncol. 2016;34(Suppl 15):1005.

10. Cardoso F, Paluch-Shimon S, Senkus E, Curigliano G, Aapro M S, André F, et al. $5^{\text {th }}$ ESO-ESMO international consensus guidelines for advanced breast cancer (ABC 5). Ann Oncol. 2020:31(12):1623-1649.

11. Cardoso F, Kyriakides S, Ohno S, Penault-Llorca F, Poortmans P, Rubio IT, et al. Early Breast Cancer: ESMO Clinical Practice Guidelines Published in 2019. Ann Oncol. 2019;30:1194-1220.

12. Brito RA, Valero V, Buzdar AU, Booser DJ, Ames F, Strom E, et al. Long-term results of combined-modality therapy for locally advanced breast cancer with ipsilateral supraclavicular metastases: The University of Texas M.D. Anderson Cancer Center experience. J Clin Oncol. 2001;19(3):628-33.

13. Perloff M, Lesnick GJ, Korzun A, Chu F, Holland JF, Thirlwell MP, et al. Combination chemotherapy with mastectomy or radiotherapy for stage III breast carcinoma: a Cancer and Leukemia Group B study. J Clin Oncol. 1988:6(2):261-9.

14. Ueno NT, Buzdar AU, Singletary SE, Ames FC, McNeese MD, Holmes FA, et al. Combined-modality treatment of inflammatory breast carcinoma: twenty years of experience at M.D. Anderson Cancer Center. Cancer Chemother Pharmacol. 1997:40(4):321-9.

15. Berg CD, Swain SM. Results of concomitantly administered chemoradiation for locally advanced non inflammatory breast cancer. Semin Radiat Oncol. 1994;4(4):226-235

16. Hortobagyi GN, Ames FC, Budzar AU, Kau SW, McNeese MD, Paulus D, et al. Management of stage III primary breast cancer with primary chemotherapy, surgery and radiation therapy. Cancer. 1988:62(12):2507-16.

17. Kuge S, Tokuda Y, Ohta M, Okumura A, Kubota M, Ninomiya S, et al. Use of metronidazole gel to control malodor in advanced and recurrent breast cancer. Jpn J Clin Oncol. 1996;26(4):207-10.

18. Rotimi VO, Durosinmi-Etti FA. The bacteriology of infected malignant ulcers. J Clin Pathol. 1984:37(5):592-5. 
19. Brusis T, Luckhaupt $H$. Fetor from ulcerated head and neck tumors. Ann Otol Rhinol Laryngol. 1989;98(8 Pt 1):615-7.

20. Ashford RF, Plant GT, Maher J, Pickering D, Coe MA, Drury A, et al. Metronidazole in smelly tumours. Lancet. 1980;1(8173):874-5.

21. Dankert J, Holloway Y, Bouma J, Van der Werf J, Wolthers BG.Metronidazole in smelly gynaecological tumours. Lancet. 1981;2(8258):1295.

22. Sparrow G, Minton M, Rubens RD, Simmons NA, Aubrey C: Metronidazole in smelly tomours. Lancet. 1980;1(8179):1185.

23. Ashford R, Plant G, Maher J, Teare L. Double-blind trial of metronidazole in malodorous ulcerating tumours. Lancet. 1984; 1(8388):1232-3.

24. Arky R. FLAGYL $®$ tablets, In Physicians' Desk Reference 49, Med Econ, Montvale; 1995. p 2323

25. Jones PH, Willis AT, Ferguson IR. Treatment of anaerobically infected pressure sores with topical metronidazole. Lancet. 1978; 1(8057):213-4.

26. Commercial version of metronidazole gel? J Pharm. 1987;18:504. (Letter)

27. Newman V, Allwood M, Oakes RA: The use of metronidazole gel to control the smell of malodorous lesions. Pallia Med. 1989:3:303-5.

28. Arky R: METROGEL®, In Physicians' Desk Reference 49, Med Econ, Montvale. pl055, 1995

29. Nomoto S, Akai T, Nomiyama H, Kuwano H, Kuwabara Y, Yoshimitsu K. A retrospective study of the effectiveness of haemostatic radiotherapy with conventional fractionation in patients with advanced cancer. J Cancer Res Ther. 2015;3:124-8.

30. Satoh E, Osanai T, Tomi Y, Nakamura M, Yonekura K, Murakata A, et al. A Case Report of Recurrent Bleeding and Massive Malodorous Effusion Due to Skin Invasion of Advanced Breast Cancer Successfully Treated with Mohs' Paste. Gan To Kagaku Ryoho. 2018;45(13):1997-1999.

31. Dharkar DV, Moses S. Palliative Mastectomy Revisited Indian J Palliat Care. 2018;24(3):359-361).

32. Dingley S, Wojda TR, Paul E, Sharpe RP. Palliative Toilet Mastectomy for Advanced Breast Cancer in Cameroon - Sometimes Doing Less is More. Internat J Academic Medicine. 2017;3(2):310-311

33. Chirappapha $P$, Lertsithichai $P$, Sukarayothin $T$, Leesombatpaiboon M, Supsamutchai $\mathrm{C}$, Kongdan Y. Oncoplastic techniques in breast surgery for special therapeutic problems. Gland Surg. 2016:5(1): 75-82

34. Verma R, Hirachan S, Singh YP. Palliative Toilet Mastectomy for Advanced Breast Cancer in a University Hospital of Nepal. JIOM Nepal. 2020;42(1):71.

35. Tukiainen $E$. Chest wall reconstruction after oncological resections. Scand J Surg. 2013:102:9-13.

36. Ellis MJ, Singh B, Miller WR, Llombart-Cussac A, Jänicke F, Mauriac L, et al. Letrozole (Femara) is a more effective inhibitor of estrogen activity than tamoxifen: evidence from a randomized phase III trial of 4 months preoperative endocrine therapy for postmenopausal women with primary invasive breast cancer. Proc Am Soc Clin Oncol 2001:abstract 1661.

37. Zucali R, Uslenghi C, Kenda R, Bonadonna G. Natural history and survival of inoperable breast cancer treated with radiotherapy and radiotherapy followed radical mastectomy. Cancer.1976; 37: 1422-1431.

38. Hortobagyi GN, Ames FC, Budzar AU, Kau SW, McNeese MD, Paulus D, et al. Management of stage III primary breast cancer with primary chemotherapy, surgery and radiation therapy. Cancer. 1988;62(12):2507-16.

39. Gradishar WJ. Inflammatory breast cancer: the evolution of multimodality treatment strategies. Semin Surg Oncol. 1996;12(5):352-63.

40. Baldini E, Gardin G, Giannessi PG, Evangelista G, Roncella M, Prochilo T, et al. Accelerated versus standard cyclophosphamide, epirubicin and 5-fluorouracil or cyclophosphamide, methotrexate and 5-fluorouracil: a randomized phase III trial in locally advanced breast cancer. Ann Oncol. 2003;14(2):227-32

41. Pons-Tostivint E, Kirova Y, Lusque A, Campone M, Geffrelot J, Mazouni $C$, et al. Survival impact of locoregional treatment of the primary tumor in de novo metastatic breast cancers in a large multicentric cohort study: a propensity score-matched analysis. Ann Surg Oncol. 2019;26(2): 356-365.

42. Co M, Ng J, Kwong A. De-novo metastatic breast cancers with or without primary tumor resection: a 10 year study. Cancer Treat Res Commun. 2019; 19:1-5.

43. Xiao W, Zou Y, Zheng S, Hu X, Liu P, Xie X, et al. Primary tumor resection in stage IV breast cancer: a systemic review and meta-analysis. Eur J Surg Oncol. 2018;44(10):1504-1512

44. Wong Y, Raghavendra A, Hatzis C, Irizarry JP, Vega T, Horowitz N, et al. Long-term survival of de novo stage IV HER2 positive breast cancers treated with HER2-targeted therapy. Oncologist. 2019; 24(3):313-318.

45. Gera R, Hage Chehade HEL, Wazir U, Tayeh S, Kasem A, Mokbel K. Locoregional therapy of the primary tumour in de novo stage IV breast cancer in 216066 patients: a meta-analysis. Sci Rep. 2020; 10(1):2952.

46. Lee JS, Toktas O, Soran A. Role of Locoregional Treatment in De Novo Stage IV Breast Cancer. Clin Med Insights Oncol. 2020;14:1179554920942440. eCollection 2020

47. Verma R, Hirachan S, Singh YP. Palliative Toilet Mastectomy for Advanced Breast Cancer in a University Hospital of Nepal. JIOM Nepal. 2020;42(1):71.

48. Srinivasa Rao N, Mythili Devi S, Babji K. Thoraco- abdominal flap for resurfacing large post mastectomy defects in locally advanced ca. Breast. Journal of Evidence based Medicine and Healthcare. 2015;2(6):699-704. 